\title{
Sexually transmitted disease in gynaecological out-patients with vaginal discharge
}

\author{
A. M. DRISCOLL, D. R. MCCOY, C. S. NICOL, AND J. BARROW \\ From the Departments of Gynaecology and Venereology, St. Thomas' Hospital, London
}

THE patients selected were those who complained specifically of vaginal discharge.

\section{Methods}

(1) Using platinum wire loops, specimens were collected from the urethra and cervix. Smears were stained by Gram's method and by a direct fluorescent antibody technique.

(2) Cultures from urethra and cervix were prepared by the use of cotton wool swabs for inoculation on to blood agar plates.

(3) A wire-loop specimen taken from the vaginal wall was stained by Gram's method for Candida albicans.

(4) A sample was collected from the vaginal wall with a spoon and put into saline; this was examined for Trichomonas vaginalis by direct microscopy and by culture. A slide was prepared and stained by Gram's method and examined for Candida. Finally Sabouraud's culture medium was inoculated.

(5) 'First drop' urines were collected and examined for T-strain mycoplasmas.

(6) A sample of blood was collected and examined by the FTA/ABS technique.

So far 34 patients have been examined; their ages ranging from 15 to 45 years. Twenty were married, eight single, two widowed, and three divorced or separated, and the marital status of one was not known.

\section{Findings}

The gonococcus was found in one patient $(2 \cdot 9$ per cent.) who also had candidosis.

Trichomoniasis was present in eight patients (23.5 per cent.); two also had candidosis, one also had T-strain mycoplasma, and one also had haemophilus vaginalis.

Seventeen patients ( 50.0 per cent.) had candidosis; trichomonads were recovered from two, $T$-strain mycoplasmas from two, and gonococci from one.

$T$-strain mycoplasmas were found in the urine of seven patients ( 20.6 per cent.), one of whom also had trichomoniasis and two candidosis.

Haemophilus vaginalis was found in one patient (2.9 per cent.), who also had trichomoniasis.

Five (14.7 per cent.) showed no abnormalities.

\section{The case of gonorrhoea}

The patient with gonorrhoea attended the Gynaecological Department with a history of vaginal discharge persisting for 5 months, and also of dyspareunia. During the previous year she had had a similar discharge for which her doctor had prescribed 'Flagyl', and had ordered the same treatment for the husband. Initially gonococci were found only in the cervix. The patient was then referred to the Department of Venereology where intracellular Gramnegative diplococci were found in the specimen from the cervix only, but gonococci were grown from cultures from both urethra and cervix, and the fluorescent antibody technique gave positive results in specimens from urethra, cervix, and rectum.

Her husband was asked to attend and was found to be asymptomatic. Clinical examination revealed no abnormality, the two-glass test showed clear urine 2 hours after previous micturition. The overnight urethral secretion was tested and urethritis was found. Gram-negative intracellular diplococci were demonstrated microscopically. He admitted extramarital exposure 9 weeks previously.

\section{Summary}

34 women with the specific complaint of vaginal discharge were tested for evidence of sexually transmitted disease. Five had no abnormality; the other 31 had gonorrhoea (1), trichomoniasis (8), candidosis (17), T-strain mycoplasmas ( 7 ), and $H$. vaginalis (1), singly or in various combinations. The investigation of the one patient with gonorrhoea and of her asymptomatic husband are described in detail.

\section{Les maladies vénériennes chez les femmes consultant en gynécologie pour une leucorrhée SOMMAIRE}

L'existence de maladies vénériennes fut recherchée chez 36 femmes consultant en gynécologie pour une leucorrhée. Rien ne fut trouvé chez 5 d'entre elles. Chez les 31 autres, on constata: gonococcie (1), trichomonase (8), candidose (17), présence de mycoplasmes souche $\mathrm{T}$ (7), et $H$. vaginalis (1), ceci à titre isolé ou en diverses associations. Les recherches chez la seule femme atteinte de gonoccie et son mari asymtomatique sont décrites en détail. 